\title{
Nonlinear Dynamic Model of PMBLDC Motor Considering Core Losses
}

\author{
Fasil, Muhammed; Mijatovic, Nenad; Jensen, Bogi Bech; Holbøll, Joachim
}

Published in:

IEEE Transactions on Industrial Electronics

Link to article, DOI:

10.1109/TIE.2017.2711536

Publication date:

2017

Document Version

Peer reviewed version

Link back to DTU Orbit

Citation (APA):

Fasil, M., Mijatovic, N., Jensen, B. B., \& Holbøll, J. (2017). Nonlinear Dynamic Model of PMBLDC Motor Considering Core Losses. IEEE Transactions on Industrial Electronics, 64(12), 9282-9280.

https://doi.org/10.1109/TIE.2017.2711536

\section{General rights}

Copyright and moral rights for the publications made accessible in the public portal are retained by the authors and/or other copyright owners and it is a condition of accessing publications that users recognise and abide by the legal requirements associated with these rights.

- Users may download and print one copy of any publication from the public portal for the purpose of private study or research.

- You may not further distribute the material or use it for any profit-making activity or commercial gain

- You may freely distribute the URL identifying the publication in the public portal

If you believe that this document breaches copyright please contact us providing details, and we will remove access to the work immediately and investigate your claim. 


\title{
Nonlinear Dynamic Model of PMBLDC Motor Considering Core Losses
}

\author{
Fasil M, Nenad M, Senior Member, IEEE, \\ Bogi BB, Senior Member, IEEE, and Joachim H, Senior Member, IEEE
}

\begin{abstract}
The phase variable model is used commonly when simulating a motor drive system with a three-phase permanent magnet brushless DC (PMBLDC) motor. The phase variable model neglects core losses and this affects its accuracy when modelling fractional-slot machines. The inaccuracy of phase variable model of fractional-slot machines can be attributed to considerable armature flux harmonics, which causes an increased core loss. This study proposes a nonlinear phase variable model of PMBLDC motor that considers the core losses induced in the stator and the rotor. The core loss model is developed based on the detailed analysis of the flux path and the variation of flux in different components of the machine. A prototype of fractional slot axial flux PMBLDC in-wheel motor is used to assess the proposed nonlinear dynamic model.
\end{abstract}

Index Terms-Brushless DC (BLDC) Machines, axial flux machines, nonlinear model, dynamic model, segmented axial torus motor.

\section{INTRODUCTION}

$\mathbf{U}$ NLIKE the two dimensional flux path of radial flux machines, the main flux in axial flux (AF) machines has a three-dimensional (3D) path. Therefore, these machines have to be analysed using techniques like magnetic equivalent circuit [1] or 3D finite element (FE) method [2] that consider 3D fluxes for obtaining accurate results. The time required to solve the 3D model of a machine makes simulating a system such as electric vehicles that include models of power electronic converter and load along with AF machines impractical. Therefore, simulating a system with AF permanent magnet brushless DC (PMBLDC) motor requires a motor model with a solution time similar to the models of other components of the system, such as linear phase variable model [3], [4], nonlinear phase variable model [5], and average value two axes model [6]. All the three models mentioned neglect core loss modelling.

There is an increased interest in fractional-slot winding machines because of the benefits such as high power density, high

Manuscript received Month $\mathrm{xx}, 2 \mathrm{xxx}$; revised Month $\mathrm{XX}$, XXXX; accepted Month $\mathrm{x}, \mathrm{xxxx}$. This work was supported by the EUFP7NANOPYME Project under Grant 310516. (Corresponding author: Fasil M.)

M. Fasil, J. Holboll, and N. Mijatovic are with the Department of Electrical Engineering, Technical University of Denmark, 2800 Kongens Lyngby, Denmark (e-mail: mfasil@elektro.dtu.dk; nm@elektro.dtu.dk; jh@elektro. dtu.dk).

B. B. Jensen is with the Department of Science and Technology, University of the Faroe Islands, 100 Tórshavn, Faroe Islands (e-mail bogibj@setur.fo).

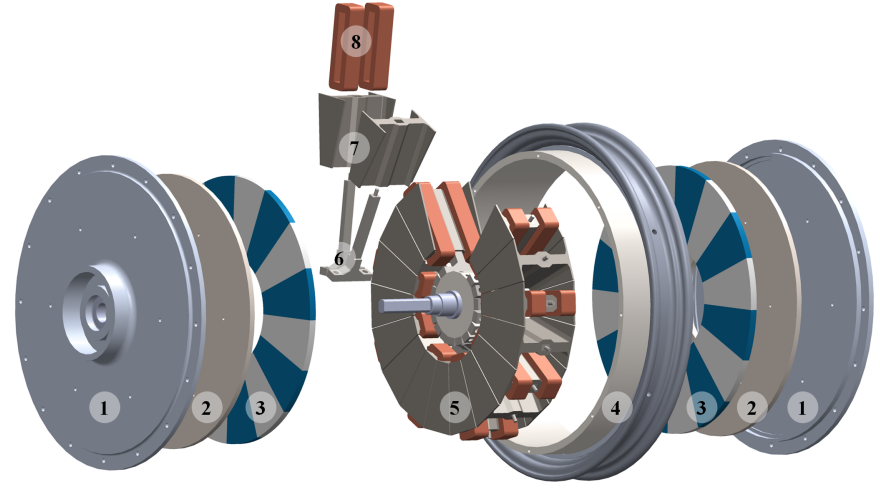

Fig. 1. Schematic of the SAT PMBLDC in-wheel motor (1. End cover, 2. rotor yoke, 3. magnet poles, 4 . wheel rim with spacer, 5 . stator, 6 . tooth holder, 7. segmented tooth, and 8. coils).

efficiency, low cogging torque, and fault tolerance [7], [8]. The fractional-slot machines have considerable rotor losses due to the rich presence of sub- and super-space harmonic components of armature flux that are not in synchronism with the rotor [9], [10]. Because of higher value of core loss in fractional-slot machines compared to integral-slot machines, the lack of core loss calculation in PMBLDC motor models could introduce considerable error in the performance simulation of fractional-slot PMBLDC machines.

In this work, a core-loss model of a segmented axial torus (SAT) PMBLDC motor is developed and incorporated into the nonlinear phase variable model of PMBLDC motor. The proposed model is evaluated using a prototype of SAT PMBLDC in-wheel motor to investigate the further areas of development of the proposed model.

\section{SAT PMBLDC IN-WHEEL MOTOR}

A SAT PMBLDC in-wheel motor with ferrite magnets as rotor poles is designed and fabricated to power an electric two-wheeler. The schematic of the SAT PMBLDC motor is shown in Fig.1. The SAT motor topology is a variation of torus slotted north-south AF motor topology and has no stator yoke [11]. The magnetically separated teeth can be wound separately before assembly and this ensures high fill factor and short end turn resulting in an efficiency improvement [12]. The specification and main geometrical dimensions of the motor are listed in TABLE I. 
TABLE I

THE RATING AND DIMENSIONS OF THE SAT PMBLDC MOTOR

\begin{tabular}{lc}
\hline \hline Parameter & Value \\
\hline The rated voltage & $48 \mathrm{~V}$ \\
The rated power output & $700 \mathrm{~W}$ \\
The rated torque & $20 \mathrm{~N} \mathrm{~m}$ \\
Outer diameter of the motor & $275 \mathrm{~mm}$ \\
Diameter ratio & 0.45 \\
Axial length of the motor & $95.8 \mathrm{~mm}$ \\
Number of stator slots-rotor poles & $18-16$ \\
Thickness of magnet poles & $7.5 \mathrm{~mm}$ \\
Length of air gap & $2 \mathrm{~mm}$ \\
Number of turns per coil & 30 \\
\hline \hline
\end{tabular}

\section{THE CORE LOSSES IN SAT PMBLDC MOTORS}

The time variation of flux density in components such as stator core, magnets, magnet retaining ring, and rotor yoke generate core losses in permanent magnet (PM) machines. Core losses can be classified as hysteresis loss, eddy current loss, and excess loss [13]. This study considers only the hysteresis and the eddy current losses. The SAT PMBLDC motor is a stator-yokeless topology, and ferrite magnets are non-conducting magnets. Therefore, the flux density variation generates losses only in the segmented stator tooth and the solid rotor yoke of the motor. The FE analysis of the SAT PMBLDC motor showed a considerable variation in the maximum value of flux densities in the tooth-tip and the remaining part of the stator tooth (the section of the tooth excluding the tooth-tip will be addressed as tooth henceforth). Therefore, the tooth-tip and the tooth are considered as two different components for loss modelling. In this work, the magnetic losses associated with the current building up and the pulse width modulation (PWM) switching of the stator current are neglected. The following part of this section will formulate expressions for calculating core losses in the stator tooth, the tooth-tip, and the rotor yoke of a SAT PMBLDC motor.

\section{A. Core losses in stator tooth-tip}

In a PM machine, the armature flux will distort the tooth flux density distribution generated by the permanent magnets. The unexcited and the excited flux density distributions on a pair of tooth faces of the SAT PMBLDC motor is shown in Fig. 2. From Fig. 2, it is clear that the armature current not only distorts the no-load field distribution of tooth-tips but also increases the maximum flux density. The flux density variation of the two stator tooth-tips, one with coil and one without coil, with rotor position is shown in Fig. 3. The flux density variations are captured from a series of static FE simulations. In each simulation step, the rotor is rotated by an angle and a pair of phases are excited with a constant current to produce a positive motoring torque. The toothtip flux densities inside the tooth tip volume are sampled at three points of a plane located at the midpoint of the toothtip thickness. The captured flux density variations can be simplified as shown in Fig. 4 to fit the core loss model for electrical machines with non-sinusoidal excitation, proposed

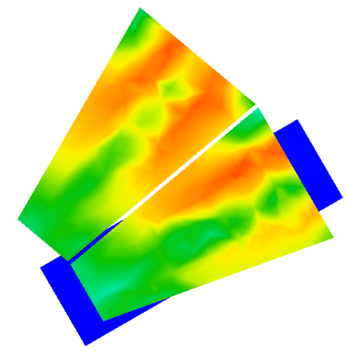

(a)

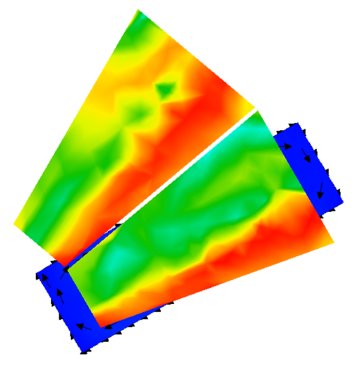

(b)

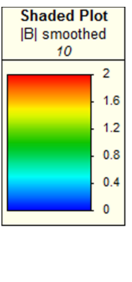

Fig. 2. Flux density distribution on stator tooth faces of the SAT PMBLDC motor. (a) No-load. (b) when the armature carries a current of $15 \mathrm{~A}$.

by Slemon and Liu [14]. The simplified flux density waveform accounts the peak flux density and the rotor displacement over which the flux density variation occurs. The simplified flux density waveform changes the polarity over angle $\alpha_{t t}$, the mean pole transition angle in electrical radians. The tooth-tip core loss per unit mass corresponding to the simplified flux density waveform is given by [14]

$$
p_{\mathrm{tt}}=K_{\mathrm{h}} f^{\alpha} B_{\mathrm{ttm}}^{\beta}+\frac{4}{\pi} K_{\mathrm{e}} \frac{f^{2} B_{\mathrm{ttm}}^{2}}{\alpha_{\mathrm{tt}}}
$$

where $K_{\mathrm{h}}, \alpha, \beta$, and $K_{\mathrm{e}}$ are the constants obtained from the curve fitting of core loss data measured for a toroidal stack of steel laminations with sinusoidal excitation, $f$ is the frequency of flux density variation, and $B_{\mathrm{ttm}}$ is the peak value of flux density at the tooth-tip.

\section{B. Core losses in stator tooth}

The flux density variation with rotor position for a tooth with coil and a tooth without coil of the SAT PMBLDC motor is shown in Fig. 5. The flux density variations are captured at the geometrical centre of the tooth because the tooth has a uniform flux density across its cross-section. The coils are carrying a current of $15 \mathrm{~A}$. The armature current affects only a peak during one cycle of tooth flux density variation and the effect on the affected peak is less pronounced as shown in Fig. 5. Therefore, the tooth flux density variation with the armature current is not considered. The tooth core loss can be calculated using the model of Slemon and Liu [14] with the help of the simplified flux density variation shown in Fig. 5. The tooth core loss per unit mass is given by [14]

$$
p_{\mathrm{t}}=K_{\mathrm{h}} f^{\alpha} B_{\mathrm{tm}}^{\beta}+\frac{4}{\pi} K_{\mathrm{e}} \frac{f^{2} B_{\mathrm{tm}}^{2}}{\alpha_{\mathrm{t}}}
$$

where, $B_{\mathrm{tm}}$ is the peak value of the tooth flux density, and $\alpha_{\mathrm{t}}$ is $2 \pi / 3$, the phase current conduction angle in electrical radians.

\section{Core losses in solid rotor yoke}

There are two reasons for the flux variation in the rotor yoke with time. The change in the reluctance seen by the rotor magnets as they move past the slot openings, and the relative speed between the armature flux and the rotor yoke. The designed motor has a $1 \mathrm{~mm}$ slot opening and this narrow slot 


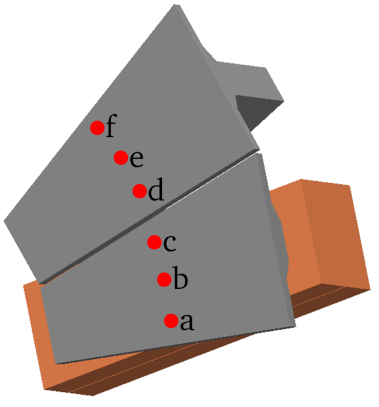

(a)

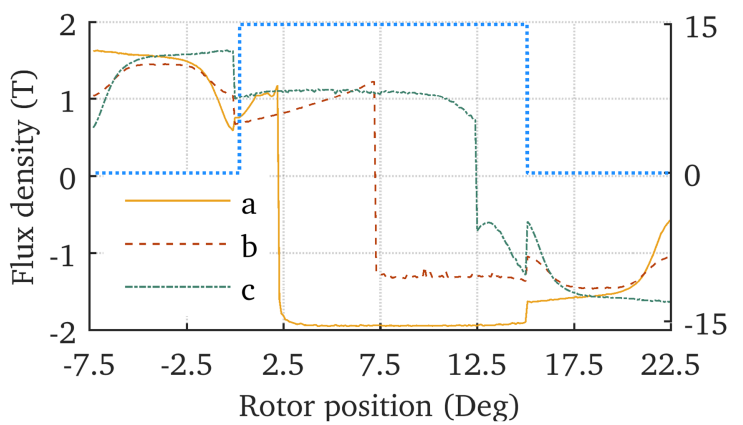

(b)

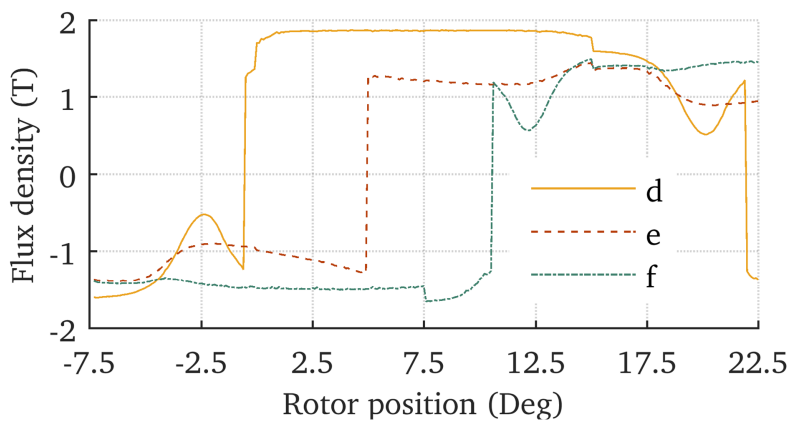

(c)

Fig. 3. The flux density variation inside the tooth tip with rotor position for six points in a plane located at the middle of a tooth-tip of the SAT PMBLDC motor, when armature carries a current of $15 \mathrm{~A}$. (a) Position of flux density sampling points in the stator. (b) Flux density variation in a tooth with current carrying coil. (c) Flux density variation in a tooth without coil.

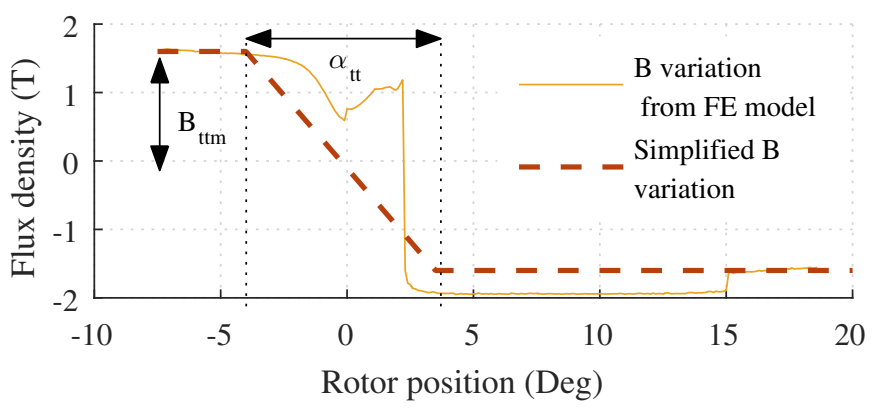

Fig. 4. Tooth-tip flux density variation and the simplified tooth-tip flux density variation of the SAT PMBLDC motor.

opening creates only a minor flux density variation in the rotor yoke as shown in Fig. 6. Therefore, the core loss generated in the rotor yoke due to slot opening is neglected because

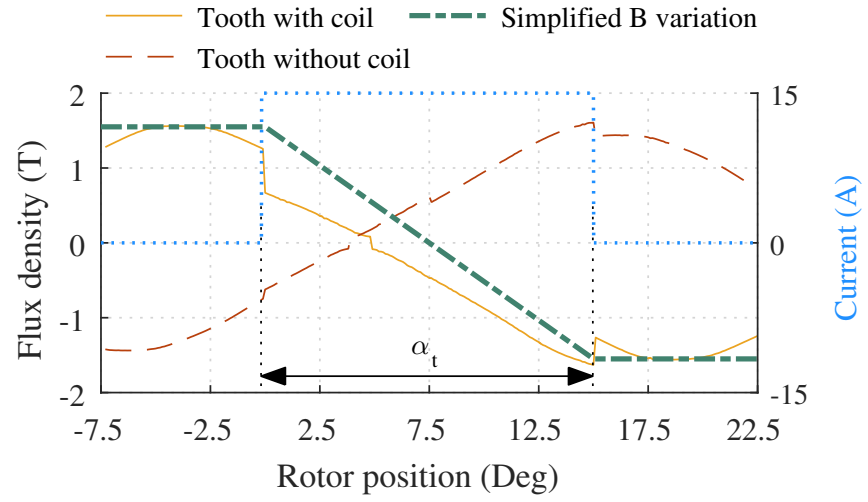

Fig. 5. The flux density variation with rotor position for a tooth with coil and a tooth without coil of the SAT PMBLDC motor, when the armature carries a current of $15 \mathrm{~A}$.

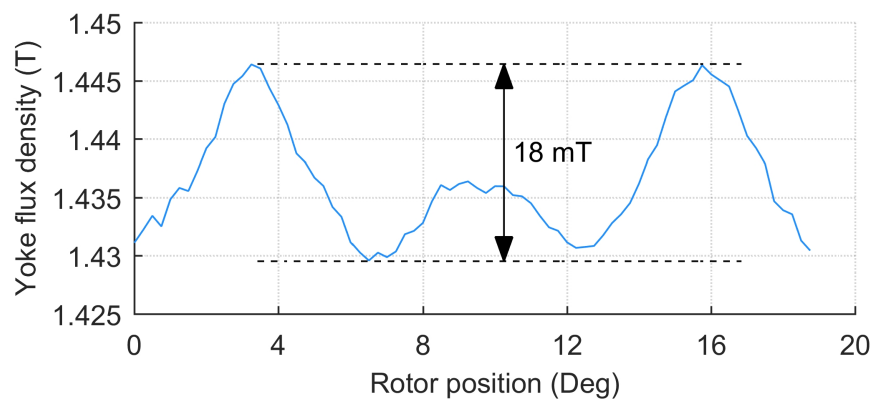

Fig. 6. The rotor yoke flux density variation of the SAT PMBLDC motor with rotor position under no-load.

the reluctance seen by magnets remains nearly constant as the rotor rotates.

The armature flux will generate both hysteresis and eddy current loss in a solid rotor yoke of a PMBLDC motor. The rotor yoke flux density of the SAT PMBLDC motor at no-load and when the armature carries a current of $20 \mathrm{~A}$ is shown in Fig. 7. Comparing no-load and load flux density distributions in yoke, it is clear that the armature flux enhances some of the no-load peaks and diminishes the others. The sections of the rotor yoke that experience the maximum flux density will have a loss corresponding to a minor hysteresis loop formed about the operating point defined by the no-load flux density $1.35 \mathrm{~T}$. The area of the minor loop will increase with armature current. However, Bottauscio et al. in their work shown that the hysteresis loss will be a smaller fraction of the total rotor losses [15], and hence, the rotor yoke hysteresis loss is not considered in this work.

The eddy current loss generated in the solid conducting rotor yoke of a PM motor by armature harmonic fluxes can be calculated using either an FE model [16] or an analytical model [17]. The studies comparing both models found that the results obtained from the analytical model are within the acceptable limits of results of the FE model [18], [19]. A 3D-FE model of a SAT PMBLDC motor will take considerably longer simulation time because of the small element size required for the accurate simulation of eddy current distribution in a solid conducting yoke [18]. Therefore, this work uses an analytical approach using a three-layer model proposed by Lawrenson 


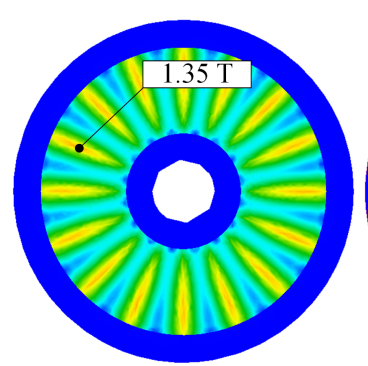

(a)

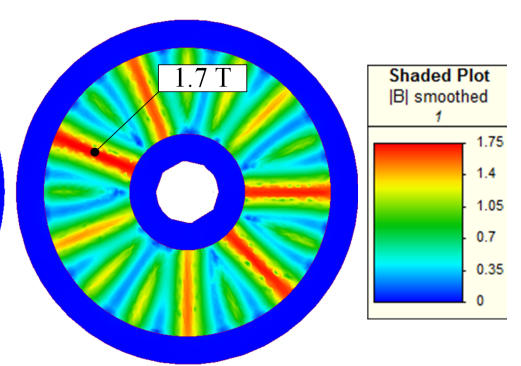

(b)
Fig. 7. The rotor yoke flux density of the SAT PMBLDC motor. (a) Noload. (b) When armature carries a current of $20 \mathrm{~A}$.

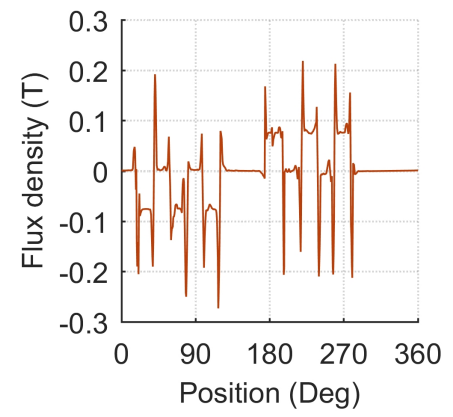

(a)

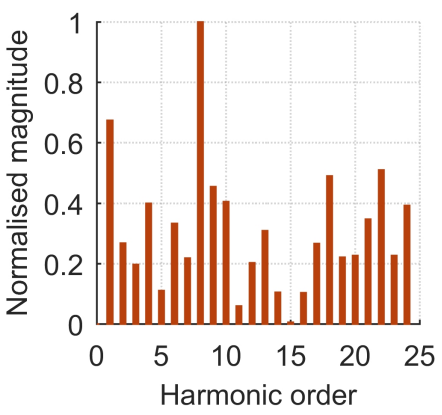

(b)
Fig. 8. The airgap flux density harmonics of the SAT PMBLDC motor, when armature carries a current of $15 \mathrm{~A}$, and the magnet flux is set to zero. (a) The flux density over a $360^{\circ}$ contour. The contour used is a circle with radius equal to the mean stator radius and located at the middle of the mechanical airgap. (b) The normalised magnitude of airgap flux density harmonics.

et al. and Oberretl [20], [21].

The airgap flux density variation of the SAT PMBLDC motor and its normalised harmonics are shown in Fig. 8. The airgap flux density variation of Fig. 8 is generated by setting the magnet flux to zero and the armature current to $15 \mathrm{~A}$. The flux density variation of Fig. 8 is rich in harmonics because of the fractional-slot concentrated winding employed in the machine. Though, the phase windings of PMBLDC motors are spatially separated from each other by $120^{\circ}$ electrical; they carry currents that have a phase difference of $180^{\circ}$ electrical. As a result, rotating armature flux is not formed in PMBLDC motors, and the armature flux is either stationary or pulsating depending upon whether the winding carries a constant current or a varying current. Consequently, the velocity of the stationary armature flux density wave of a PMBLDC motor with respect to its rotor is the rotational speed of the machine.

The linear velocity of the armature flux density wave of a PMBLDC motor with respect to its rotor is given by

$$
v=2 \pi n R_{\text {Ymean }}
$$

where, $n$ is the rotational speed of the machine in revolutions per second, and $R_{\text {Ymean }}$ is the mean radius of the rotor yoke. The wave length, $\lambda_{i}$ of the $i^{\text {th }}$ harmonic of flux density wave is given by

$$
\lambda_{i}=\frac{2 \pi R_{\text {Ymean }}}{i}
$$

The angular frequency of the $i^{\text {th }}$ harmonic of flux density wave is given by

$$
\omega_{i}=\frac{2 \pi v}{\lambda_{i}}
$$

Substituting (3) and (4) to (5)

$$
\omega_{i}=2 \pi \times 2 \pi n R_{\text {Ymean }} \times \frac{i}{2 \pi R_{\text {Ymean }}}=2 \pi n i
$$

The skin depth of $i^{\text {th }}$ harmonic of flux density wave is given by

$$
\delta_{i}=\sqrt{\frac{2 \rho_{\mathrm{Fe}}}{\mu_{\mathrm{Fe}} \omega_{i}}}
$$

where, $\rho_{\mathrm{Fe}}$ is the resistivity, and $\mu_{\mathrm{Fe}}$ is the average permeability of the rotor yoke material, which is normally made of solid soft iron in PMBLDC motors. Substituting (6) to (7)

$$
\delta_{i}=\sqrt{\frac{\rho_{\mathrm{Fe}}}{i \pi \mu_{\mathrm{Fe}} n}}
$$

The eddy current loss generated in a rotor yoke due to $i^{\text {th }}$ harmonic of flux density wave can be calculated as [17]

$$
P_{\text {Lrye } i}=\frac{\left|B_{i}\right|^{2} v^{2} \delta_{i}}{4 \rho_{\mathrm{Fe}}} \times A_{\mathrm{ry}}
$$

where, $\left|B_{i}\right|$ is the magnitude of $i^{\text {th }}$ harmonic of the armature flux density wave and $A_{\mathrm{ry}}$ area of the rotor yoke face. Substituting (3) and (8) to (9)

$$
P_{\text {Lrye } i}=\left|B_{i}\right|^{2} R_{\text {Ymean }}^{2} A_{\text {ry }} \sqrt{\frac{\pi^{3}}{i \rho_{\mathrm{Fe}} \mu_{\mathrm{Fe}}}} \times n^{1.5}
$$

The total eddy current loss generated due to armature flux density wave corresponding to a motor speed of $n$ is given by

$$
P_{\text {Lrye }}=n^{1.5} \times R_{\text {Ymean }}^{2} A_{\mathrm{ry}} \sqrt{\frac{\pi^{3}}{\rho_{\mathrm{Fe}} \mu_{\mathrm{Fe}}}} \sum_{i=1}^{\infty} \frac{\left|B_{i}\right|^{2}}{\sqrt{i}}
$$

The second term of (11) is independent of the rotational speed of the PMBLDC motor and can be expressed as a function of source current, $i_{\mathrm{s}}$ as

$$
f_{\text {yoke eddy loss }}\left\{i_{\mathrm{s}}\right\}=R_{\text {Ymean }}^{2} A_{\mathrm{ry}} \sqrt{\frac{\pi^{3}}{\rho_{\mathrm{Fe}} \mu_{\mathrm{Fe}}}} \sum_{i=1}^{\infty} \frac{\left|B_{i}\right|^{2}}{\sqrt{i}}
$$

Therefore, (11) can be written as

$$
P_{\text {Lrye }}=n^{1.5} \times f_{\text {yoke eddy loss }}\left\{i_{\mathrm{s}}\right\}
$$

Rotor yoke eddy current loss in a PMBLDC motor with more than one rotor yoke can be calculated as

$$
P_{\text {Lrye }}=n_{\mathrm{y}} n^{1.5} \times f_{\text {yoke eddy loss }}\left\{i_{\mathrm{s}}\right\}
$$

where, $n_{\mathrm{y}}$ is the number of rotor yokes in the motor. The (14) can be expressed in terms of the operating frequency of the motor similar to equations for core losses in the stator tooth-tip (1) and the stator tooth (2) as

$$
P_{\text {Lrye }}=n_{\mathrm{y}}\left(\frac{f}{p}\right)^{1.5} \times f_{\text {yoke eddy loss }}\left\{i_{\mathrm{s}}\right\}
$$

where, $p$ is the number of pole pairs of PMBLDC motor. 


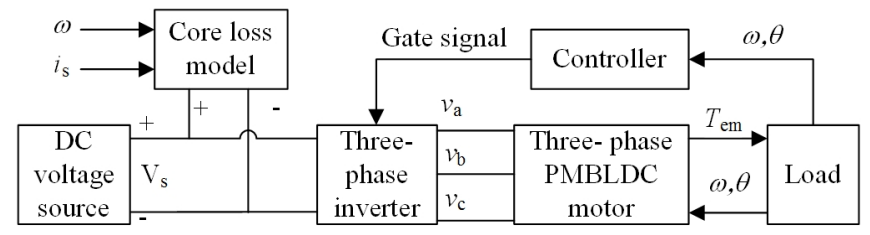

Fig. 9. The block diagram of nonlinear dynamic model of three-phase PMBLDC motor.

\section{NONLINEAR DYNAMIC MODEL OF THREE-PHASE PMBLDC MOTOR}

A block diagram of the proposed nonlinear dynamic model of three-phase PMBLDC motor is shown in Fig. 9. It consists of DC voltage source, a three-phase inverter, a PMBLDC motor, a load, a controller, and a core loss model. The model is implemented in Matlab-Simulink ${ }^{\mathrm{TM}}$. This section discusses the implementation of individual blocks of the dynamic model of a PMBLDC motor drive.

\section{A. Three-phase PMBLDC motor model}

The motor model solves the voltage equations and the torque equation of the motor. The SAT PMBLDC motor has an alternate tooth winding. The tooth without coil will have fluxes from the two nearby coils. However, the flux from one coil will not link with other coil. Therefore, mutual coupling of coils is not present in SAT PMBLDC motor. The voltage equation of a phase is given by [22]

$$
\begin{aligned}
v & =i R+L \frac{d i}{d t}+e \\
& =i R+L \frac{d i}{d t}+\frac{d \psi(\theta, i)}{d \theta} \omega \\
& =i R+L \frac{d i}{d t}+\psi^{\prime}(\theta, i) \omega
\end{aligned}
$$

where, $v$ is the applied phase voltage, $i$ is the phase current, $R$ is the phase resistance, $L$ is the phase inductance, $e$ is the phase back EMF, $\psi$ is the flux linkage of a phase as a function of the rotor position in mechanical degree, $\theta$ and the phase current, $\psi^{\prime}$ is the derivative of $\psi$, and $\omega$ is the angular velocity of the rotor. The flux linkage is obtained from a series of static 3D FE simulations. The instantaneous electromagnetic torque of the motor, $T_{\mathrm{em}}$ can be expressed as

$$
T_{\mathrm{em}}=\psi_{\mathrm{a}}^{\prime}\left(\theta, i_{\mathrm{a}}\right) i_{a}+\psi_{\mathrm{b}}^{\prime}\left(\theta, i_{\mathrm{b}}\right) i_{b}+\psi_{\mathrm{c}}^{\prime}\left(\theta, i_{\mathrm{c}}\right) i_{c}+T_{\mathrm{cg}}(\theta)
$$

where, $T_{\mathrm{cg}}(\theta)$ is the cogging torque as a function of the rotor position. The implementation of voltage equations and torque equation of a three-phase PMBLDC motor is shown in Fig. 10 and Fig. 11 respectively. Both the models uses a 2-D lookup table of the flux linkage derivative as a function of phase current and rotor position, calculated from a series of static FE simulations, to model the non-ideal back EMF waveform and the effect armature reaction on it.

\section{B. Core loss model}

The loss model incorporates hysteresis and eddy current losses in the stator core and eddy current loss in the rotor

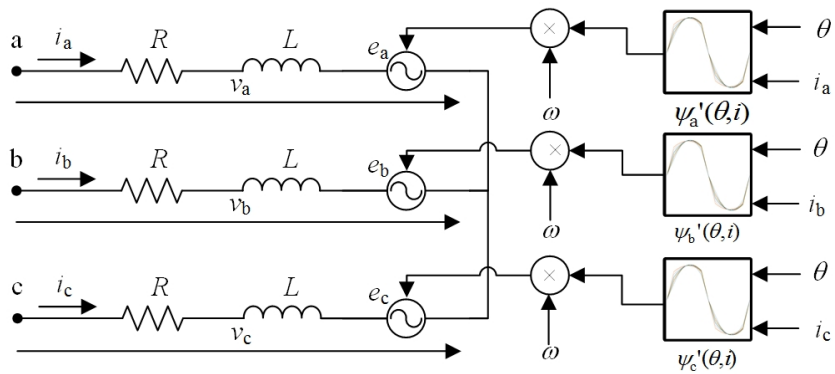

Fig. 10. The model for solving the voltage equation of a three-phase PMBLDC motor.

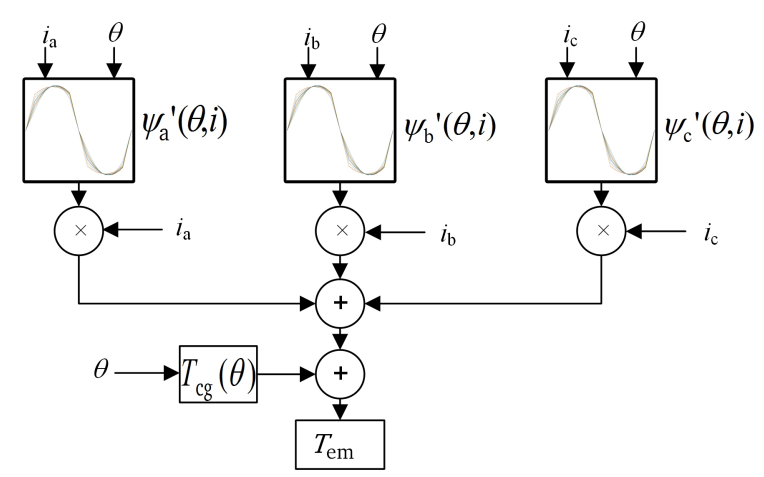

Fig. 11. The model for solving the torque equation of a three-phase PMBLDC motor.

yoke into the nonlinear phase variable model of a PMBLDC motor. If $M_{\mathrm{stt}}$ is the mass of all tooth-tips and $M_{\mathrm{st}}$ is the mass of all tooth, the total core losses generated in the stator core can be calculated from (1) and (2) as

$$
\begin{aligned}
P_{\mathrm{cs}}= & K_{\mathrm{h}} f^{\alpha}\left(M_{\mathrm{stt}} B_{\mathrm{ttm}}^{\beta}+M_{\mathrm{st}} B_{\mathrm{tm}}^{\beta}\right) \\
& +\frac{4}{\pi} K_{\mathrm{e}} f^{2}\left(\frac{M_{\mathrm{stt}} B_{\mathrm{ttm}}^{2}}{\alpha_{\mathrm{tt}}}+\frac{M_{\mathrm{st}} B_{\mathrm{tm}}^{2}}{\alpha_{\mathrm{t}}}\right)
\end{aligned}
$$

Total core loss can be obtained by adding (15) and (18),

$$
\begin{aligned}
P_{\mathrm{c}}= & n_{\mathrm{y}}\left(\frac{f}{p}\right)^{1.5} \times f_{\text {yoke eddy loss }}\left\{i_{\mathrm{s}}\right\} \\
& +K_{\mathrm{h}} f^{\alpha}\left(M_{\mathrm{stt}} B_{\mathrm{ttm}}^{\beta}+M_{\mathrm{st}} B_{\mathrm{tm}}^{\beta}\right) \\
& +\frac{4}{\pi} K_{\mathrm{e}} f^{2}\left(\frac{M_{\mathrm{stt}} B_{\mathrm{ttm}}^{2}}{\alpha_{\mathrm{tt}}}+\frac{M_{\mathrm{st}} B_{\mathrm{tm}}^{2}}{\alpha_{\mathrm{t}}}\right)
\end{aligned}
$$

The core loss equation (19) of a PMBLDC motor is solved using the model shown in Fig. 12. The core loss model uses two look-up tables, one for the peak tooth-tip flux density and another one for the rotor yoke eddy current loss function. The look-up table of peak tooth-tip flux density vs. armature current can be generated from the same set of FE models used to calculate the variation of flux linkage with rotor position and armature current. The look-up table of the rotor yoke eddy current loss function is obtained by solving FE models of a PMBLDC motor without magnet flux for different armature current. Though, removing magnet flux will enhance the magnitude of stator flux density harmonics by lowering the saturation level of the flux path, the approach will help 


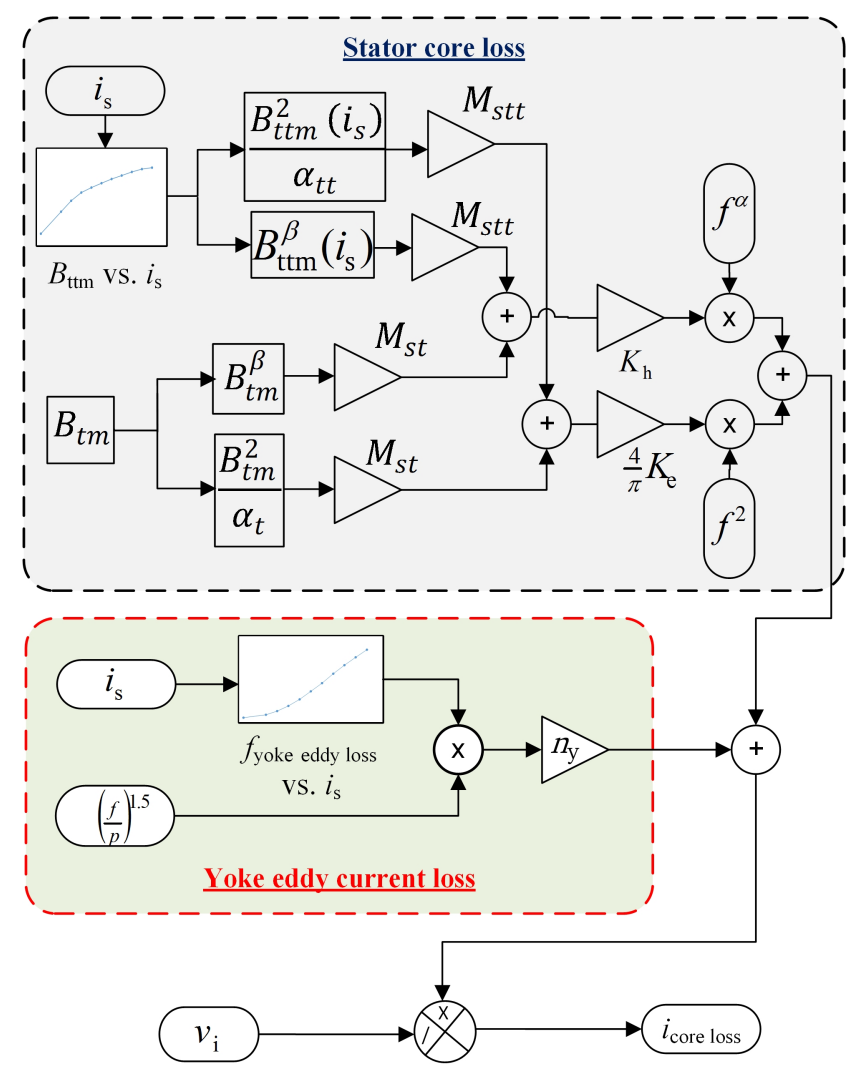

Fig. 12. The core loss model of a PMBLDC motor.

to capture low amplitude sub-harmonic components, which can penetrate deep into the yoke and induce most of the losses [16], [17]. The core loss model calculates the core loss component of the current, and in a Simulink model, this current will be drawn from the voltage source via a block named controlled current source, connected across the voltage source.

\section{Power electronic converter model}

A standard three bridge converter from the Simulink library is used in the model. Further, a controller is modelled to generate the gate pulses for the converter based on the rotor position so that a positive shaft torque is produced.

\section{Load model}

The electromagnetic torque developed in the motor has to work against the load torque, inertia of rotating components, and moving friction. The equation governing the load behaviour can be written as

$$
T_{\mathrm{em}}=T_{\mathrm{L}}+j \frac{d \omega}{d t}+b \omega
$$

where, $T_{\mathrm{L}}$ is the load torque, $j$ is the moment of inertia of rotating parts of the motor and the load, and $b$ is the constant of moving friction.

\section{SIMULATED AND EXPERIMENTAL RESULTS}

The dynamic model proposed in this work is used to simulate the SAT PMBLDC motor prototype driving a constant

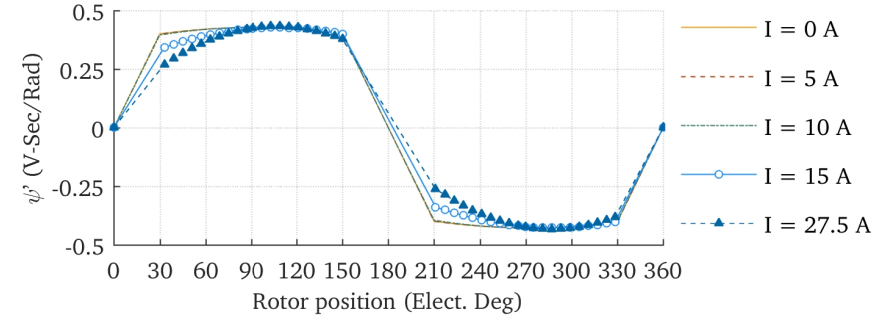

Fig. 13. The variation of the flux-linkage-derivative with rotor position for different phase current obtained from a series of static FE simulations of the ferrite magnet SAT PMBLDC motor prototype.

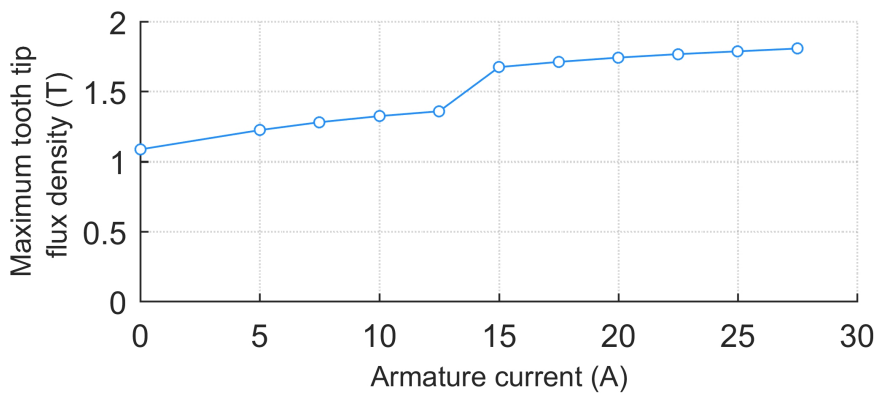

Fig. 14. The variation of the peak value of the tooth-tip flux density with armature current obtained from the FE simulation of the SAT PMBLDC motor.

torque load in a test bench. A comparative study of results of the simulation and the testing is presented to assess the model and to identify areas of improvements in the dynamic modelling of the PMBLDC motor.

\section{A. Nonlinear dynamic model parameters}

The variation of flux-linkage-derivative of the motor with rotor position for different values of phase current is shown in Fig. 13. The simulated peak tooth-tip flux density variation of the prototype motor with armature current is shown in Fig. 14, and the change in the curve from $15 \mathrm{~A}$ can be attributed to saturation of stator laminations. The change of rotor yoke eddy current loss function with armature current is shown in Fig. 15. Cogging torque of the motor is not considered because the FE analysis of a reduced sized model found that the peak-to-peak value of cogging torque is only $16 \mathrm{mN} \mathrm{m}$. The phase resistance value of $56 \mathrm{~m} \Omega$ and the phase inductance value of $1.8 \mathrm{mH}$, obtained from the FE model, are used in the simulation.

\section{B. Experimental setup for testing SAT PMBLDC motor}

The test setup to measure the performance of SAT PMBLDC in-wheel motor is shown in Fig. 16. The test bench consists of a four-quadrant drive, speed reduction gears, torque and speed sensor, a monitor to record torque and speed, a BLDC motor controller and a DC power supply. The fourquadrant drive is configured to work as a generator, and it can act as a constant torque load to the motor.

\section{Discussion}

The variation of the flux-linkage-derivative with rotor position is used to estimate the line back EMF at $340 \mathrm{rpm}$. 


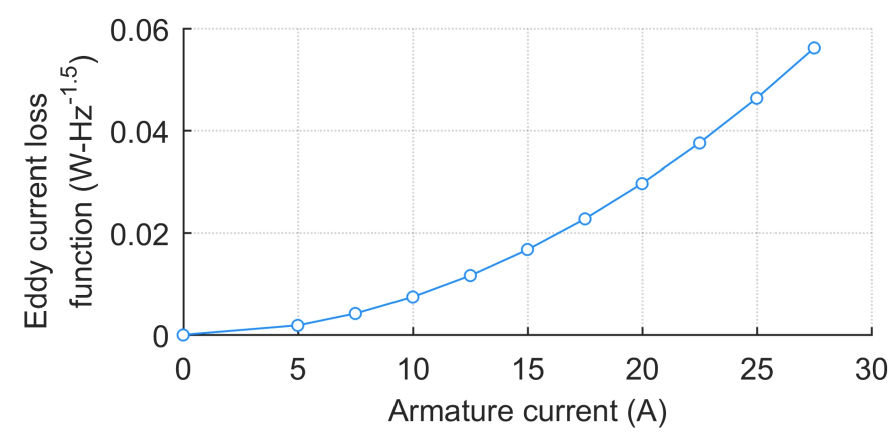

Fig. 15. The values of yoke eddy current loss function of the SAT PMBLDC motor design for different armature current.

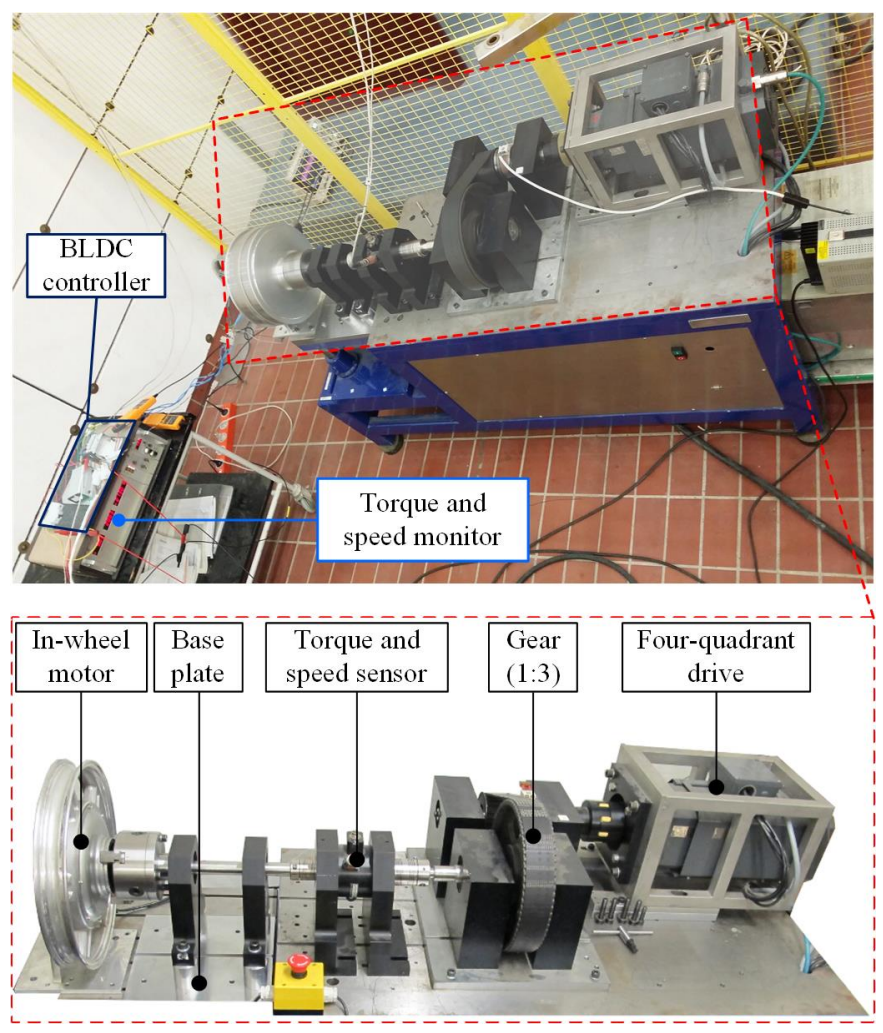

Fig. 16. The experimental setup to measure the performance of the SAT PMBLDC in-wheel motor.

The calculated line back EMF is plotted in Fig. 17 along with the waveform obtained from the back EMF test of the motor. The deviation of the test back EMF waveform from the FE simulated back EMF waveform can be attributed to manufacturing variations of the motor compared to the assembly simulated in the FE software. The major variations observed in the prototype are in widths of slot openings, in dimensions of interpolar gaps, and in thickness of magnets.

The phase current waveforms obtained from the dynamic modelling and the testing of the prototype motor is plotted in Fig. 18. The waveform corresponds to a load torque of $10 \mathrm{Nm}$ at a speed of $300 \mathrm{rpm}$. The efficiency map obtained from the test and the simulation of the prototype ferrite magnet SAT PMBLDC motor is shown in Fig. 19. The simulated current waveform closely follows that of the test. However, there is considerable variation in maximum efficiencies and

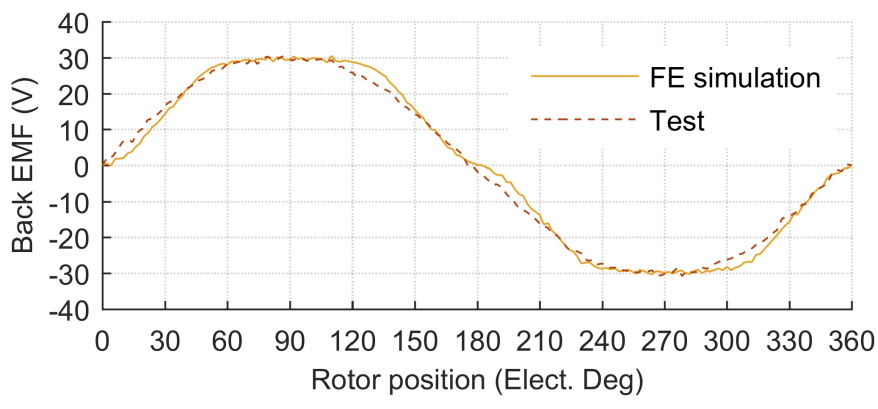

Fig. 17. The test and the FE simulated line back EMF waveforms of the prototype ferrite magnet SAT PMBLDC motor.

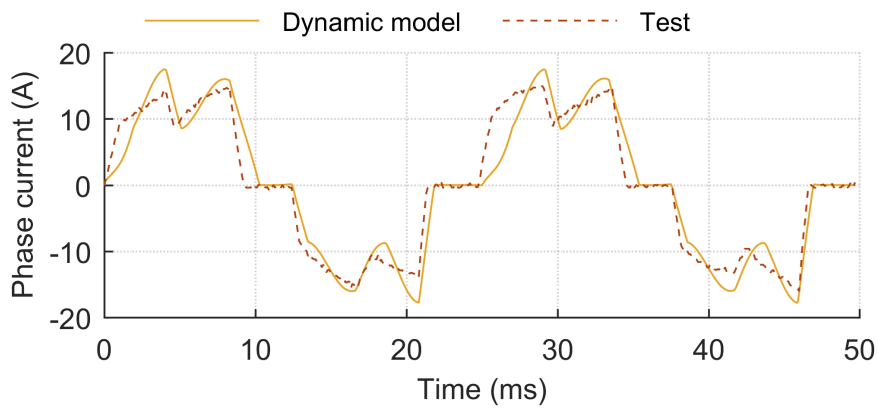

Fig. 18. The test and simulated phase current waveforms of the SAT PMBLDC motor.

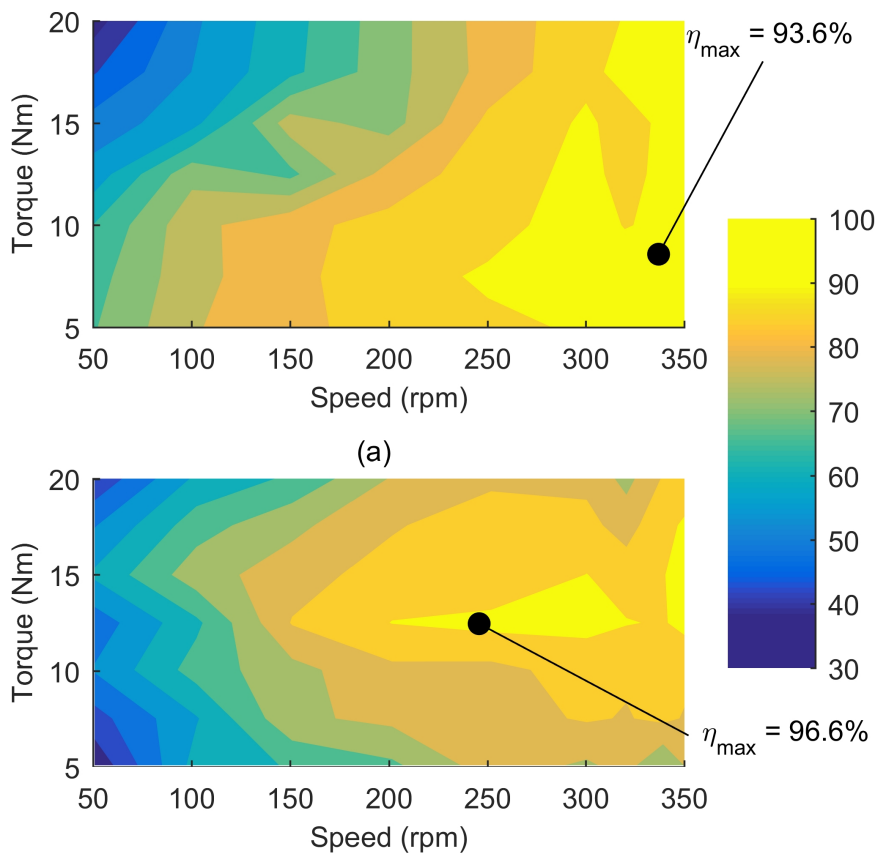

(b)

Fig. 19. The efficiency map of the SAT PMBLDC motor.(a) From the dynamic model. (b) From the testing. 
distributions of efficiency bands of the dynamic model and the test data. The reasons for the difference between the simulated and the tested efficiency maps of the ferrite magnet prototype has been explored, and they are

1) The simplified windage and friction loss model used in the dynamic model cannot expect to be accurate, especially when the motor is operating with an efficiency more than $90 \%$. The windage loss characterisation of the PMBLDC motor requires a detailed study using nonmagnetic dummy rotors and computational fluid dynamic models [23], [24]. The lack of mechanical loss characterisation prevents the extraction of electromagnetic losses other than the conduction loss from the test data. The segregation of losses will help to improve the overall accuracy of the dynamic model by individually validating each loss model and thus improving the loss models used in the study.

2) The prototype motor uses a commercial controller, and the detailed operation and the component layout of the controller were not available. The dynamic model of the PMBLDC motor discussed in this work uses a basic sixpulse inverter. Using an in-house developed PMBLDC motor controller would help to model and validate the switching and conduction losses in the controller.

3) The prototype motor has a considerable vibration between $310 \mathrm{rpm}$ and $330 \mathrm{rpm}$ only when connected to the test bench, and the readings of the torque and the speed from the sensors were oscillating substantially during this speed range.

\section{CONCLUSION}

This work discusses the development of a core loss model and incorporating it into the nonlinear phase variable model of three-phase PMBLDC motor. The model is developed for SAT motor topology. A theoretical study has been presented in which the core loss is modelled as a function of peak flux densities of flux paths, the armature current, and the speed of the machine. The model captures nonlinearities in core losses of the stator and the solid rotor yoke with the help of two lookup tables derived from the static FE model of the machine. The first look-up table relates the maximum tooth tip flux density and the armature current, and the second look-up table relates eddy current in the rotor yoke and the armature current.

A comparative study of the results of the dynamic modelling and the test results of a SAT PMBLDC motor is carried out. The motor was operating with an efficiency of more than $90 \%$, and the accuracy with which all electromagnetic and mechanical losses are modelled is critical to estimate the system performance accurately at this level of efficiency. Therefore, it is concluded that a loss segregation study is required to complete the validation of core loss model.

\section{REFERENCES}

[1] R. Ni, G. Wang, X. Gui, and D. Xu, "Investigation of d and q -Axis Inductances Influenced by Slot-Pole Combinations Based on Axial Flux Permanent-Magnet Machines," IEEE Trans. Ind. Electron., vol. 61, no. 9, pp. 4539-4551, sep 2014.
[2] B. Xia, J.-X. Shen, P. C.-K. Luk, and W. Fei, "Comparative Study of Air-Cored Axial-Flux Permanent-Magnet Machines With Different Stator Winding Configurations," IEEE Trans. Ind. Electron., vol. 62, no. 2, pp. 846-856, feb 2015.

[3] T. M. Jahns, "Torque Production in Permanent-Magnet Synchronous Motor Drives with Rectangular Current Excitation," IEEE Trans. Ind. Appl., vol. IA-20, no. 4, pp. 803-813, jul 1984.

[4] C.-T. Pan and E. Fang, "A Phase-Locked-Loop-Assisted Internal Model Adjustable-Speed Controller for BLDC Motors," IEEE Trans. Ind. Electron., vol. 55, no. 9, pp. 3415-3425, sep 2008.

[5] O. Mohammed, S. Liu, and Z. Liu, "A phase variable model of brushless dc motors based on finite element analysis and its coupling with external circuits," IEEE Trans. Magn., vol. 41, no. 5, pp. 1576-1579, may 2005.

[6] M. Jagiela, T. Garbiec, J. Gwozdz, and J. Kolodziej, "Fast steady-state field-circuit model for SMPM-BLDC motors driven from 120 Deg and 180 Deg quasi-square wave inverters," IEEE Trans. Magn., vol. PP, no. 99, pp. $1-1,2015$.

[7] A. EL-Refaie, "Fractional-Slot Concentrated-Windings Synchronous Permanent Magnet Machines: Opportunities and Challenges," IEEE Trans. Ind. Electron., vol. 57, no. 1, pp. 107-121, jan 2010.

[8] G. De Donato, F. Giulii Capponi, G. A. Rivellini, and F. Caricchi, "Integral-Slot Versus Fractional-Slot Concentrated-Winding AxialFlux Permanent-Magnet Machines: Comparative Design, FEA, and Experimental Tests," IEEE Trans. Ind. Appl., vol. 48, no. 5, pp. 1487-1495, sep 2012.

[9] E. Fornasiero, N. Bianchi, and S. Bolognani, "Slot Harmonic Impact on Rotor Losses in Fractional-Slot Permanent-Magnet Machines," IEEE Trans. Ind. Electron., vol. 59, no. 6, pp. 2557-2564, jun 2012.

[10] A. Masmoudi and A. Masmoudi, "3-D Analytical Model With the End Effect Dedicated to the Prediction of PM Eddy-Current Loss in FSPMMs," IEEE Trans. Magn., vol. 51, no. 4, pp. 1-11, apr 2015.

[11] T. Woolmer and M. McCulloch, "Analysis of the Yokeless And Segmented Armature Machine," in 2007 IEEE Int. Electr. Mach. Drives Conf., vol. 1. IEEE, may 2007, pp. 704-708.

[12] T. J. Woolmer and M. McCulloch, "Axial flux permanent magnet machines: a new topology for high performance applications," in IET Hybrid Veh. Conf. 2006, vol. 2006. IEE, 2006, pp. 27-42.

[13] G. Bertotti, "General properties of power losses in soft ferromagnetic materials," IEEE Trans. Magn., vol. 24, no. 1, pp. 621-630, 1988.

[14] G. Slemon and X. Liu, "Core losses in permanent magnet motors," IEEE Trans. Magn., vol. 26, no. 5, pp. 1653-1655, 1990.

[15] O. Bottauscio, G. Pellegrino, P. Guglielmi, M. Chiampi, and A. Vagati, "Rotor loss estimation in permanent magnet machines with concentrated windings," IEEE Trans. Magn., vol. 41, no. 10, pp. 3913-3915, oct 2005.

[16] N. Bianchi, D. Durello, and A. Fasolo, "Relationship Between Rotor Losses and Size of Permanent-Magnet Machines," IEEE Trans. Ind. Appl., vol. 49, no. 5, pp. 2015-2023, sep 2013.

[17] R. Di Stefano and F. Marignetti, "Electromagnetic Analysis of Axial-Flux Permanent Magnet Synchronous Machines With Fractional Windings With Experimental Validation," IEEE Trans. Ind. Electron., vol. 59, no. 6, pp. 2573-2582, jun 2012.

[18] R.-J. Wang and M. Kamper, "Calculation of Eddy Current Loss in Axial Field Permanent-Magnet Machine With Coreless Stator," IEEE Trans. Energy Convers., vol. 19, no. 3, pp. 532-538, sep 2004.

[19] D. Liu, A. Jassal, H. Polinder, and J. Ferreira, "Validation of eddy current loss models for permanent magnet machines with fractional-slot concentrated windings," in 2013 Int. Electr. Mach. Drives Conf. IEEE, may 2013, pp. 678-685.

[20] P. Lawrenson, P. Reece, and M. Ralph, "Tooth-ripple losses in solid poles," Proc. Inst. Electr. Eng., vol. 113, no. 4, p. 657, 1966.

[21] K. Oberretl, "Eddy Current Losses in Solid Pole Shoes of Synchronous Machines at No-Load and on Load," IEEE Trans. Power Appar. Syst., vol. PAS-91, no. 1, pp. 152-160, jan 1972.

[22] T. J. E. Miller, Brushless permanent-magnet and reluctance motor drives. Oxford University Press, 1989.

[23] Fang Deng, "An improved iron loss estimation for permanent magnet brushless machines," IEEE Trans. Energy Convers., vol. 14, no. 4, pp. $1391-1395,1999$.

[24] R. Wrobel, G. Vainel, C. Copeland, T. Duda, D. Staton, and P. H. Mellor, "Investigation of Mechanical Loss Components and Heat Transfer in an Axial-Flux PM Machine," IEEE Trans. Ind. Appl., vol. 51, no. 4, pp. 3000-3011, jul 2015. 